\title{
ECONOMIC ASPECTS OF PRETREATMENT TECHNOLOGIES BEFORE REVERSE OSMOSIS
}

\author{
Jolanta GUMIŃSKA ${ }^{1 *}$, Marcin KŁOS ${ }^{2}$ \\ ${ }^{1}$ Silesian University of Technology, Faculty of Energy and Environmental Engineering; \\ jolanta.guminska@polsl.pl, ORCID: 0000-0002-2625-0257 \\ ${ }^{2}$ Silesian University of Technology, Faculty of Energy and Environmental Engineering; marcin.j.klos@polsl.pl, \\ ORCID: 0000-0002-4990-1593 \\ * Correspondence author
}

Purpose: The article presents the results of economic efficiency analysis for the construction of preliminary water purification systems before the membrane demineralization process. Two types of pre-treatment systems were analysed: conventional system and ultrafiltration.

Design/methodology/approach: The profitability analysis of the construction of water pretreatment systems (WPS) before membrane demineralization was carried out based on technological, economic and financial assumptions.

Findings: The simulations allowed determining the boundary conditions for the profitability of this type of investment in the form of the adopted treatment technology, conditioned by the water pre-treatment method. The simulation results showed that with the current investment and operating costs of the combined rapid filtration process on three-layer beds and dynamic sorption and, alternatively, membrane pressure ultrafiltration, the choice of the latter pretreatment method allows obtaining significantly better economic results.

Originality/value: The results of the cost analysis of both tested variants indicate that the use of pressure ultrafiltration as the final process is much more effective than the conventional treatment system based on rapid filtration and dynamic sorption.

Keywords: pre-treatment, water demineralization, ultrafiltration, rapid filtration, GAC.

Category of the paper: research paper.

\section{Introduction}

Reverse osmosis (RO) membrane technology is one of the most important technologies for industrial water treatment. Premature failure of reverse osmosis (RO) membrane elements due to identified or unidentified membrane fouling substances (biofouling, organic fouling, inorganic scaling and colloidal fouling) leads to higher operating pressure, flux decline, frequent chemical cleaning and shorter membrane life. In terms of the fouling places fouling is 
the accumulation of undesired deposits on the membrane surface (surface fouling) or inside the membrane pores (internal fouling) (Jiang et al., 2017; Lin et al., 2014; She at al., 2016). The fouling mechanisms of low pressure membranes differs from those of high pressure membranes. For low pressure MF and UF, pore adsorption and clogging are more common. For high pressure RO membranes, surface fouling is more frequent because of the relative compact and nonporous nature of RO membrane (Greenlee et al., 2009). Compared with internal fouling, surface fouling can be controlled more easily through improving feed water hydrodynamic conditions or chemical cleaning (Hoek et al., 2008; She et al., 2016). That's why, it is usually more reversible than internal fouling. However, depending on feed water compositions and their interactions with membrane, both negative fouling processes i.e. surface fouling and internal fouling can be irreversible.

Foulants are usually removed by a series of source water treatment processes (coagulation, flocculation and $\mathrm{pH}$ adjustment) followed by conventional granular media (anthracite and sand) filtration (Kim, and Kang, 1998; Simpson, 2008; Haberkamp et al., 2007; Gumińska, and Kłos, 2011; LeChevallier et al., 1992). Advances in microfiltration (MF) and ultrafiltration (UF) membrane technologies resulted in using membrane pre-treatment in seawater desalination plants. Both granular media and membrane filtration pre-treatment technologies show pros and cons depending on the source water quality. Therefore, selecting the most suitable pre-treatment technology for a given project a comprehensive performance and economic analysis should be made (Voutchkov, 2010; Huehmer, 2009; Gumiński et al., 2017).

In order to control membrane fouling, a variety of methods are applied such as pre-treatment, membrane monitoring, membrane cleaning, surface modification (Al-Juboori, and Yusaf, 2012; Brehant et al., 2002; Henthorne, and Boysen, 2015; Nguyen et al., 2016).

The paper presents financial simulations that allow to determine the impact of the selected method of water pre-treatment before desalination processes, in particular the reverse osmosis process. As part of the work, financial simulations were carried out based on the calculation model, which allows for effective assessment and selection of a better solution from analysed technological variants due to economic criteria of investment effectiveness.

\section{Methodology of economic and financial analysis}

The profitability analysis of the construction of water pre-treatment systems (WPS) before membrane demineralization was carried out based on technological, economic and financial assumptions.

To assess profitability indicators of water pre-treatment systems, discount methods were used. These methods are based on the changing value of money over time, and are widely applied to analyse the level of economic profitability of investment projects (Berens, and 
Hawranek, 1993; Sierpińska, and Jachna, 2005). Main methods used in such an analysis are as follows:

- the NPV (Net Present Value) method,

- the IRR (Internal Rate of Return) method,

- the DPP (Discounted Payback Period) method,

- the PI (Profitability Index) method.

Input data enabling the determination of indicators' values in discount methods are net cash flow. They are estimated as the balance of incoming and outgoing cash within the whole period of an investment phase and an operating phase. Net cash flow in a single year is estimated making use of a direct method or an indirect method, due to the accounting regulations (Accounting Act amended on 9 November 2000). To assess the profitability indicators in this article, the calculative model was prepared based on an indirect method i.e. net cash flow for each year of an investment is a result of the net profit/loss and corrections (capital expenditure and the depreciation of fixed assets).

Technological assumptions are as follows:

- The technological system with preliminary water purification in the process of coagulation, sedimentation, filtration and dynamic sorption determined as Variant 1. It consists of three gravity rapid filters with a three-layer bed (anthracite, quartz sand, garnet) and two granular activated carbon filters (dynamic sorption) of the same construction as the previous filters. Filtration and sorption systems are preceded by coagulation operated in multi-chamber reactors in two process lines with a net capacity of $210 \mathrm{~m}^{3} / \mathrm{h}$ each. The block diagram of the first variant is presented in the Figure 1.

The conventional coagulation technological line consists of a multi-chamber reactor consisting of a rapid mixing chamber with a mechanical stirrer, a two-section flocculation chamber with mechanical mixers and a horizontal lamella settling tank.

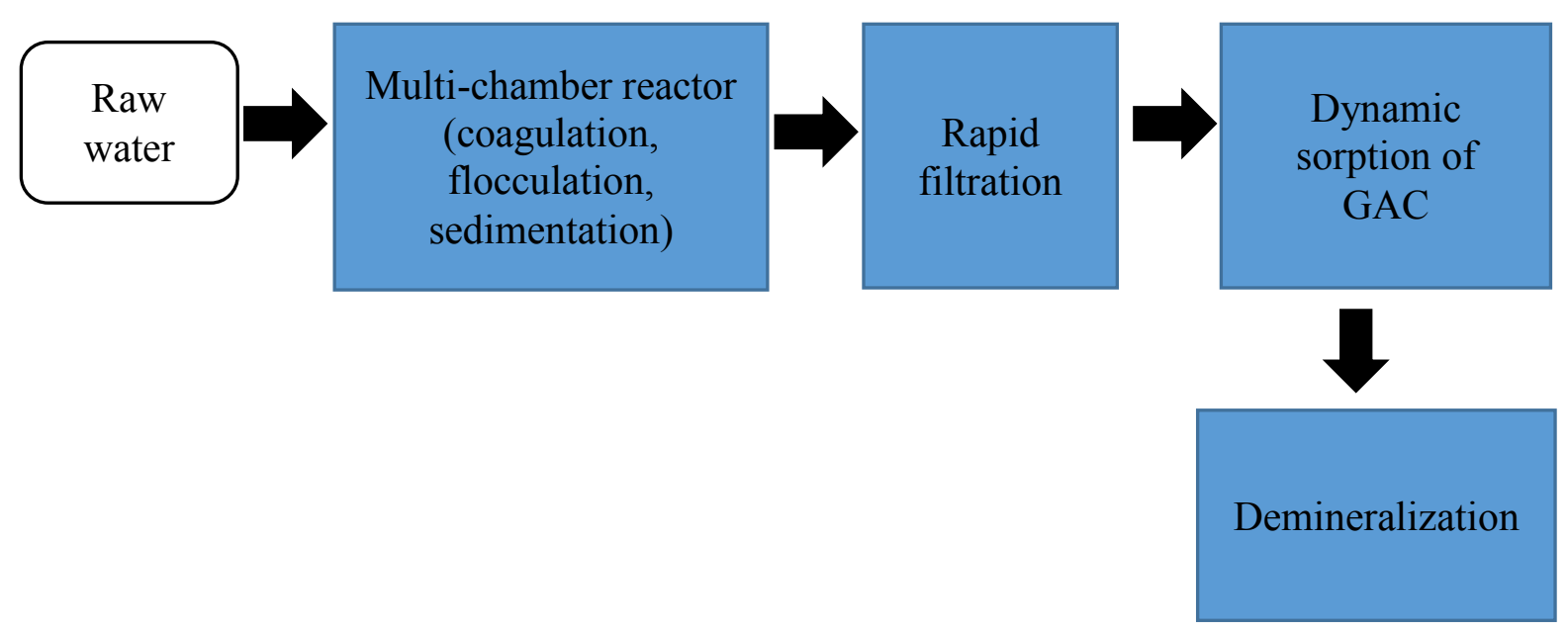

Figure 1. Technological scheme of Variant 1. 
- The technological system with preliminary water purification in the process of coagulation/flocculation, sedimentation and pressure ultrafiltration, referred to as Variant 2, consists of pressure ultrafiltration carried out in 4 ultrafiltration lines, each of which is equipped with 20 ultrafiltration modules with a membrane area of one module equal to $90 \mathrm{~m} 2$. The block diagram of the second variant is presented in the Figure 2.

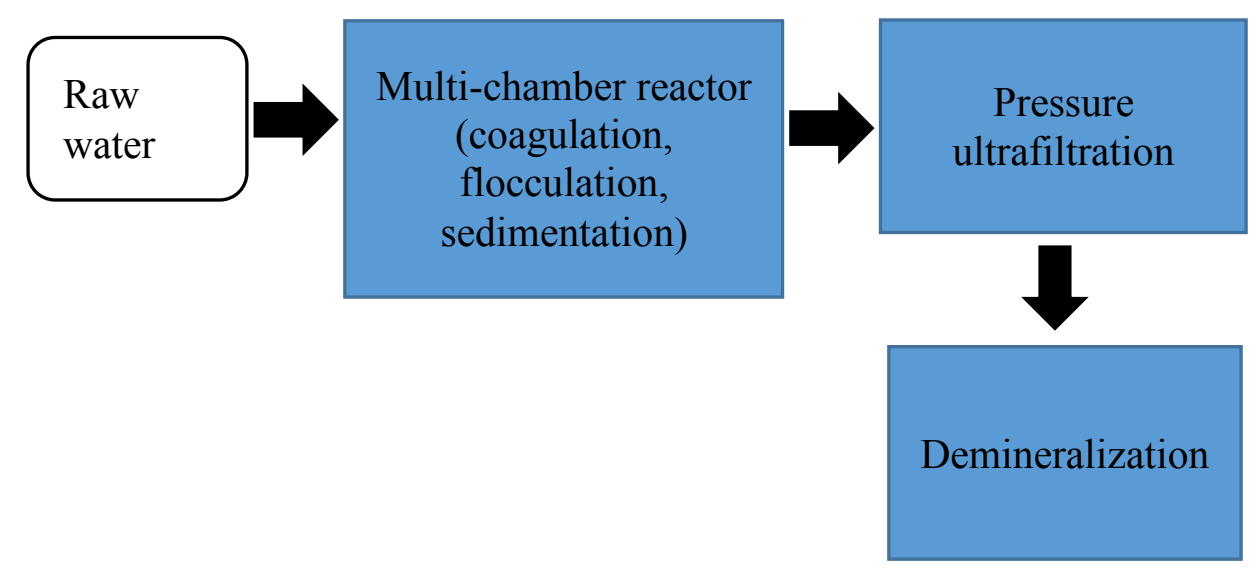

Figure 2. Technological scheme of Variant 2.

The ultrafiltration installation, similarly to Variant 1, was preceded by conventional treatment in multi-chamber reactors in two technological lines with a capacity of $210 \mathrm{~m} 3 / \mathrm{h}$ net each. The coagulation/flocculation/sedimentation installation, as in Variant 1, consists of a rapid mixing chamber with a mechanical stirrer, a two-section flocculation chamber with mechanical mixers and a horizontal lamella sedimentation tank.

- Pre-treatment water system capacity, defined as nominal production capacity $400 \mathrm{~m}^{3} / \mathrm{h}$.

- The volume of activated carbon in contact chamber used in Variant $1-135 \mathrm{~m}^{3}-$ calculated for the contact time with an empty bed (in English: Empty Bed Contact Time) of 20 minutes. The exchange of activated carbon takes place after 2 years of operation due to exhaustion of sorption capacity.

- The pressure ultrafiltration system assumes replacement of $100 \%$ membrane modules during 4 years of operation.

The economic and financial assumptions were as follow:

- the financial and economic analysis was based on 3 discount methods i.e. NPV (Net Present Value), IRR (Internal Rate of Return), PI (Profitability Index) and DPP (Discounted Payback Period),

- the calculative model, in all variants, takes into account the following economic parameters:

- capital expenditure of a pre-treatment installation,

- additional costs associated with the maintenance of a pre-treatment installation, 
- GAC replacement costs taking into account the cost of a pre-treatment installation,

- the costs of depreciation of water pre-treatment installation fixed assets.

- the economic and financial analysis, taking into account changes in the parameters determining the net cash flows, was carried out for 2 variants:

- Variant 1 - construction of coagulation, sedimentation, rapid filtration and dynamic sorption system,

- Variant 2 - construction of coagulation, sedimentation and a pressure ultrafiltration system.

- the capital expenditure of various technological systems was established on the basis of actual cost of technological systems (without expenses for land and infrastructure) of similar technical characteristics:

- a coagulation, sedimentation, rapid filtration and dynamic sorption system (Variant 1) - 10100000 PLN.

- a coagulation, sedimentation and a pressure ultrafiltration system (Variant 2) 7900000 PLN.

- the operating costs of individual technological systems have been determined for the maximum efficiency of the installation, taking into account the costs of electricity, necessary reagents, purchase of raw water and operation of the entire water pretreatment system. However, they do not take into account the costs of sludge management in the scope of backwash water and post-coagulation sludge management. They are as follows:

- the annual cost of operating the coagulation and sedimentation system was calculated at 1,680,000 PLN.

- the annual cost of operating the filtration system and dynamic sorption - 185,000 PLN.

- the annual cost of ultrafiltration system operation - 320,000 PLN,

- costs of replacing activated carbon in Variant 1 every 2 years.

- to determine the discount rate $(3.72 \%)$ an assumed risk premium was $2 \%$ and WIBOR1Y at $1.72 \%$ (on 31.07.2019).

\section{Comparative analysis of variants of preliminary water purification}

The economic analysis was undertaken to assess comparatively the profitability level of two variants:

- Variant 1 - the system of coagulation, sedimentation, rapid filtration and dynamic sorption, 
Table 1.

Cash flows in Variant 1 (with the system of rapid filtration and sorption; water price $=2 \mathrm{PLN} / \mathrm{m}^{3}$ )

\begin{tabular}{|c|c|c|c|c|c|c|c|c|c|c|c|}
\hline Id. & Specification & 2019 & 2020 & 2021 & 2022 & 2023 & 2024 & 2025 & 2026 & 2027 & 2028 \\
\hline 1. & Capital expenditure & $10,100,000.00$ & & & & & & & & & \\
\hline 2. & Total costs & $2,885,000.00$ & $2,185,000.00$ & $145,000.00$ & $2,185,000.00$ & $3,145,000.00$ & $2,385,000.00$ & $3,145,000.00$ & $2,185,000.00$ & $3,145,000.00$ & $2,185,000.00$ \\
\hline 2.1. & Explotation costs of coagulation and sedimentation system & $1,680,000.00$ & $1,680,000.00$ & $1,680,000.00$ & $1,680,000.00$ & $1,680,000.00$ & $1,680,000.00$ & $1,680,000.00$ & $1,680,000.00$ & $1,680,000.00$ & $1,680,000.00$ \\
\hline 2.2. & Costs of small renovation of coagulation and sedimentation system & $200,000.00$ & 0.00 & 0.00 & 0.00 & 0.00 & $200,000.00$ & 0.00 & 0.00 & 0.00 & 0.00 \\
\hline 2.3. & Costs of big renovation of coagulation and sedimentation system & $500,000.00$ & 0.00 & 0.00 & 0.00 & 0.00 & 0.00 & 0.00 & 0.00 & 0.00 & 0.00 \\
\hline 2.4. & Costs of active carbon replacement & 0.00 & 0.00 & $960,000.00$ & 0.00 & $960,000.00$ & 0.00 & $960,000.00$ & 0.00 & $960,000.00$ & 0.00 \\
\hline 2.5. & Amortization & $505,000.00$ & $505,000.00$ & $505,000.00$ & $505,000.00$ & $505,000.00$ & $505,000.00$ & $505,000.00$ & $505,000.00$ & $505,000.00$ & $505,000.00$ \\
\hline 3. & Operational cash flow & $6,720,000.00$ & $6,720,000.00$ & $6,720,000.00$ & $6,720,000.00$ & $6,720,000.00$ & $6,720,000.00$ & $6,720,000.00$ & $6,720,000.00$ & $6,720,000.00$ & $6,720,000.00$ \\
\hline 3.1. & Revenues from water sales & $6,720,000.00$ & $6,720,000.00$ & $6,720,000.00$ & $6,720,000.00$ & $6,720,000.00$ & $6,720,000.00$ & $6,720,000.00$ & $6,720,000.00$ & $6,720,000.00$ & $6,720,000.00$ \\
\hline 4. & Gross profit (3. - 2.) & $3,835,000.00$ & $4,535,000.00$ & $3,575,000.00$ & $4,535,000.00$ & $3,575,000.00$ & $4,335,000.00$ & $3,575,000.00$ & $4,535,000.00$ & $3,575,000.00$ & $4,535,000.00$ \\
\hline 5. & $\operatorname{Tax}(\mathrm{CIT})$ & $728,650.00$ & $861,650.00$ & $679,250.00$ & $861,650.00$ & $679,250.00$ & $823,650.00$ & $679,250.00$ & $861,650.00$ & $679,250.00$ & $861,650.00$ \\
\hline 6. & Net profit & $3,106,350.00$ & $3,673,350.00$ & $2,895,750.00$ & $3,673,350.00$ & $2,895,750.00$ & $3,511,350.00$ & $2,895,750.00$ & $3,673,350.00$ & $2,895,750.00$ & $3,673,350.00$ \\
\hline 7 & Total net cash flow $(6 .+2.5 .-1)$ & $-6,488,650.00$ & $4,178,350.00$ & $3,400,750.00$ & $4,178,350.00$ & $3,400,750.00$ & $4,016,350.00$ & $3,400,750.00$ & $4,178,350.00$ & $3,400,750.00$ & $4,178,350.00$ \\
\hline 8 & Discounted NCF & $-6,488,650.00$ & $4,028,490.17$ & $3,161,183.38$ & $\begin{array}{r}3,744,702.25 \\
\end{array}$ & $2,938,493.09$ & $\begin{array}{l}3,345,946.65 \\
\end{array}$ & $\begin{array}{l}2,731,490.27 \\
\end{array}$ & $3,235,692.63$ & $2,539,069.81$ & $\begin{array}{r}3,007,753.52 \\
\end{array}$ \\
\hline 9 & Cumulative discounted NCF & $-6,488,650.00$ & $-2,460,159.83$ & $701,023.55$ & $4,445,725.80$ & $7,384,218.89$ & $10,730,165.54$ & $13,461,655.81$ & $16,697,348.44$ & $19,236,418.25$ & $22,244,171.76$ \\
\hline
\end{tabular}

\begin{tabular}{|c|c|c|c|c|c|c|c|c|c|c|c|}
\hline Id. & Specification & 2029 & 2030 & 2031 & 2032 & 2033 & 2034 & 2035 & 2036 & 2037 & 2038 \\
\hline 1. & Capital expenditure & & & & & & & & & & \\
\hline 2. & Total costs & $3,845,000.00$ & $2,185,000.00$ & $3,145,000.00$ & $2,185,000.00$ & $3,145,000.00$ & $2,385,000.00$ & $3,145,000.00$ & $2,185,000.00$ & $3,145,000.00$ & $2,185,000.00$ \\
\hline 2.1. & Explotation costs of coagulation and sedimentation system & $1,680,000.00$ & $1,680,000.00$ & $1,680,000.00$ & $1,680,000.00$ & $1,680,000.00$ & $1,680,000.00$ & $1,680,000.00$ & $1,680,000.00$ & $1,680,000.00$ & $1,680,000.00$ \\
\hline 2.2. & Costs of small renovation of coagulation and sedimentation system & $200,000.00$ & 0.00 & 0.00 & 0.00 & 0.00 & $200,000.00$ & 0.00 & 0.00 & 0.00 & 0.00 \\
\hline 2.3. & Costs of big renovation of coagulation and sedimentation system & $500,000.00$ & 0.00 & 0.00 & 0.00 & 0.00 & 0.00 & 0.00 & 0.00 & 0.00 & 0.00 \\
\hline 2.4. & Costs of active carbon replacement & $960,000.00$ & 0.00 & $960,000.00$ & 0.00 & $960,000.00$ & 0.00 & $960,000.00$ & 0.00 & $960,000.00$ & 0.00 \\
\hline 2.5. & Amortization & $505,000.00$ & $505,000.00$ & $505,000.00$ & $505,000.00$ & $505,000.00$ & $505,000.00$ & $505,000.00$ & $505,000.00$ & $505,000.00$ & $505,000.00$ \\
\hline 3. & Operational cash flow & $6,720,000.00$ & $6,720,000.00$ & $6,720,000.00$ & $6,720,000.00$ & $6,720,000.00$ & $6,720,000.00$ & $6,720,000.00$ & $6,720,000.00$ & $6,720,000.00$ & $6,720,000.00$ \\
\hline 3.1. & Revenues from water sales & $6,720,000.00$ & $6,720,000.00$ & $6,720,000.00$ & $6,720,000.00$ & $6,720,000.00$ & $6,720,000.00$ & $6,720,000.00$ & $6,720,000.00$ & $6,720,000.00$ & $6,720,000.00$ \\
\hline 4. & Gross profit (3. - 2.) & $2,875,000.00$ & $4,535,000.00$ & $3,575,000.00$ & $4,535,000.00$ & $3,575,000.00$ & $4,335,000.00$ & $3,575,000.00$ & $4,535,000.00$ & $3,575,000.00$ & $4,535,000.00$ \\
\hline 5. & Tax (CIT) & $546,250.00$ & $861,650.00$ & $679,250.00$ & $861,650.00$ & $679,250.00$ & $823,650.00$ & $679,250.00$ & $861,650.00$ & $679,250.00$ & $861,650.00$ \\
\hline 6. & Net profit & $2,328,750.00$ & $3,673,350.00$ & $2,895,750.00$ & $3,673,350.00$ & $2,895,750.00$ & $3,511,350.00$ & $2,895,750.00$ & $3,673,350.00$ & $2,895,750.00$ & $3,673,350.00$ \\
\hline 7 & Total net cash flow $(6 .+2.5 .-1)$ & $2,833,750.00$ & $4,178,350.00$ & $3,400,750.00$ & $4,178,350.00$ & $3,400,750.00$ & $4,016,350.00$ & $3,400,750.00$ & $4,178,350.00$ & $3,400,750.00$ & $4,178,350.00$ \\
\hline 8 & Discounted NCF & $1,966,692.46$ & $2,795,871.63$ & $2,193,939.31$ & $2,598,915.81$ & $2,039,386.75$ & $2,322,169.57$ & $1,895,721.68$ & $2,245,650.56$ & $1,762,177.13$ & $2,087,455.19$ \\
\hline 9 & Cumulative discounted NCF & $24,210,864.22$ & $27,006,735.85$ & $29,200,675.16$ & $31,799,590.96$ & $33,838,977.71$ & $36,161,147.29$ & 38,056,868.97 & 40,302,519.53 & $42,064,696.66$ & $44,152,151.86$ \\
\hline
\end{tabular}


Table 2.

Cash flows in Variant 2 (with the system of pressure ultrafiltration; water price $=2 \mathrm{PLN} / \mathrm{m}^{3}$ )

\begin{tabular}{|c|c|c|c|c|c|c|c|c|c|c|c|}
\hline Id. & Specification & 2019 & 2020 & 2021 & 2022 & 2023 & 2024 & 2025 & 2026 & 2027 & 2028 \\
\hline 1. & Capital expenditure & $7,900,000.00$ & 0.00 & 0.00 & 0.00 & 0.00 & 0.00 & 0.00 & 0.00 & 0.00 & 0.00 \\
\hline 2. & Total costs & $2,775,000.00$ & $2,075,000.00$ & $2,255,000.00$ & $2,075,000.00$ & $2,255,000.00$ & $2,275,000.00$ & $2,255,000.00$ & $2,075,000.00$ & $2,255,000.00$ & $2,075,000.00$ \\
\hline 2.1. & Explotation costs of coagulation and sedimentation system & $1,680,000.00$ & $1,680,000.00$ & $1,680,000.00$ & $1,680,000.00$ & $1,680,000.00$ & $1,680,000.00$ & $1,680,000.00$ & $1,680,000.00$ & $1,680,000.00$ & $1,680,000.00$ \\
\hline 2.2. & Costs of small renovation of coagulation and sedimentation system & $200,000.00$ & 0.00 & 0.00 & 0.00 & 0.00 & $200,000.00$ & 0.00 & 0.00 & 0.00 & 0.00 \\
\hline 2.3. & Costs of big renovation of coagulation and sedimentation system & $500,000.00$ & 0.00 & 0.00 & 0.00 & 0.00 & 0.00 & 0.00 & 0.00 & 0.00 & 0.00 \\
\hline 2.4. & Costs of active carbon replacement & 0.00 & 0.00 & $180,000.00$ & 0.00 & $180,000.00$ & 0.00 & $180,000.00$ & 0.00 & $180,000.00$ & 0.00 \\
\hline 2.5. & Amortization & $395,000.00$ & $395,000.00$ & $395,000.00$ & $395,000.00$ & $395,000.00$ & $395,000.00$ & $395,000.00$ & $395,000.00$ & $395,000.00$ & $395,000.00$ \\
\hline 3. & Operational cash flow & $6,720,000.00$ & $6,720,000.00$ & $6,720,000.00$ & $6,720,000.00$ & $6,720,000.00$ & $6,720,000.00$ & $6,720,000.00$ & $6,720,000.00$ & $6,720,000.00$ & $6,720,000.00$ \\
\hline 3.1. & Revenues from water sales & $6,720,000.00$ & $6,720,000.00$ & $6,720,000.00$ & $6,720,000.00$ & $6,720,000.00$ & $6,720,000.00$ & $6,720,000.00$ & $6,720,000.00$ & $6,720,000.00$ & $6,720,000.00$ \\
\hline 3.2 . & Other revenues & 0.00 & 0.00 & 0.00 & 0.00 & 0.00 & 0.00 & 0.00 & 0.00 & 0.00 & 0.00 \\
\hline 4. & Gross profit (3. - 2.) & $3,945,000.00$ & $4,645,000.00$ & $4,465,000.00$ & $4,645,000.00$ & $4,465,000.00$ & $4,445,000.00$ & $4,465,000.00$ & $4,645,000.00$ & $4,465,000.00$ & $4,645,000.00$ \\
\hline 5. & $\operatorname{Tax}(\mathrm{CIT})$ & $749,550.00$ & $882,550.00$ & $848,350.00$ & $882,550.00$ & $848,350.00$ & $844,550.00$ & $848,350.00$ & $882,550.00$ & $848,350.00$ & $882,550.00$ \\
\hline 6. & Net profit & $3,195,450.00$ & $3,762,450.00$ & $3,616,650.00$ & $3,762,450.00$ & $3,616,650.00$ & $3,600,450.00$ & $3,616,650.00$ & $3,762,450.00$ & $3,616,650.00$ & $3,762,450.00$ \\
\hline 7 & Total net cash flow $(6 .+2.5 .-1)$ & $-4,309,550.00$ & $4,157,450.00$ & $4,011,650.00$ & $4,157,450.00$ & $4,011,650.00$ & $3,995,450.00$ & $4,011,650.00$ & $4,157,450.00$ & $4,011,650.00$ & $4,157,450.00$ \\
\hline 8 & Discounted NCF & $-4,309,550.00$ & $4,008,339.76$ & $3,729,048.39$ & $3,725,971.34$ & $3,466,354.72$ & $3,328,535.24$ & $3,222,166.57$ & $3,219,507.77$ & $2,995,180.30$ & $2,992,708.81$ \\
\hline 9 & Cumulative discounted NCF & $-4,309,550.00$ & \begin{tabular}{|c|c|}
$-301,210.24$ \\
\end{tabular} & $3,427,838.15$ & $7,153,809.50$ & $10,620,164.22$ & $13,948,699.46$ & $17,170,866.03$ & $20,390,373.80$ & $23,385,554.11$ & $26,378,262.91$ \\
\hline
\end{tabular}

\begin{tabular}{|c|c|c|c|c|c|c|c|c|c|c|c|}
\hline Id. & Specification & 2029 & 2030 & 2031 & 2032 & 2033 & 2034 & 2035 & 2036 & 2037 & 2038 \\
\hline 1. & Capital expenditure & 0.00 & 0.00 & 0.00 & 0.00 & 0.00 & 0.00 & 0.00 & 0.00 & 0.00 & 0.00 \\
\hline 2. & Total costs & $2,955,000.00$ & $2,075,000.00$ & $2,255,000.00$ & $2,075,000.00$ & $2,255,000.00$ & $2,275,000.00$ & $2,255,000.00$ & $2,075,000.00$ & $2,255,000.00$ & $2,075,000.00$ \\
\hline 2.1. & Explotation costs of coagulation and sedimentation system & $1,680,000.00$ & $1,680,000.00$ & $1,680,000.00$ & $1,680,000.00$ & $1,680,000.00$ & $1,680,000.00$ & $1,680,000.00$ & $1,680,000.00$ & $1,680,000.00$ & $1,680,000.00$ \\
\hline 2.2. & Costs of small renovation of coagulation and sedimentation system & $200,000.00$ & 0.00 & 0.00 & 0.00 & 0.00 & $200,000.00$ & 0.00 & 0.00 & 0.00 & 0.00 \\
\hline 2.3 . & Costs of big renovation of coagulation and sedimentation system & $500,000.00$ & 0.00 & 0.00 & 0.00 & 0.00 & 0.00 & 0.00 & 0.00 & 0.00 & 0.00 \\
\hline 2.4. & Costs of active carbon replacement & $180,000.00$ & 0.00 & $180,000.00$ & 0.00 & $180,000.00$ & 0.00 & $180,000.00$ & 0.00 & $180,000.00$ & 0.00 \\
\hline 2.5. & Amortization & $395,000.00$ & $395,000.00$ & $395,000.00$ & $395,000.00$ & $395,000.00$ & $395,000.00$ & $395,000.00$ & $395,000.00$ & $395,000.00$ & $395,000.00$ \\
\hline 3. & Operational cash flow & $6,720,000.00$ & $6,720,000.00$ & $6,720,000.00$ & $6,720,000.00$ & $6,720,000.00$ & $6,720,000.00$ & $6,720,000.00$ & $6,720,000.00$ & $6,720,000.00$ & $6,720,000.00$ \\
\hline 3.1. & Revenues from water sales & $6,720,000.00$ & $6,720,000.00$ & $6,720,000.00$ & $6,720,000.00$ & $6,720,000.00$ & $6,720,000.00$ & $6,720,000.00$ & $6,720,000.00$ & $6,720,000.00$ & $6,720,000.00$ \\
\hline 3.2. & Other revenues & 0.00 & 0.00 & 0.00 & 0.00 & 0.00 & 0.00 & 0.00 & 0.00 & 0.00 & 0.00 \\
\hline 4. & Gross profit $(3 .-2)$. & $3,765,000.00$ & $4,645,000.00$ & $4,465,000.00$ & $4,645,000.00$ & $4,465,000.00$ & $4,445,000.00$ & $4,465,000.00$ & $4,645,000.00$ & $4,465,000.00$ & $4,645,000.00$ \\
\hline 5. & $\operatorname{Tax}(\mathrm{CIT})$ & $715,350.00$ & $882,550.00$ & $848,350.00$ & $882,550.00$ & $848,350.00$ & $844,550.00$ & $848,350.00$ & $882,550.00$ & $848,350.00$ & $882,550.00$ \\
\hline 6. & Net profit & $3,049,650.00$ & $3,762,450.00$ & $3,616,650.00$ & $3,762,450.00$ & $3,616,650.00$ & $3,600,450.00$ & $3,616,650.00$ & $3,762,450.00$ & $3,616,650.00$ & $3,762,450.00$ \\
\hline 7 & Total net cash flow $(6 .+2.5 .-1)$ & $3,444,650.00$ & $4,157,450.00$ & $4,011,650.00$ & $4,157,450.00$ & $4,011,650.00$ & $3,995,450.00$ & $4,011,650.00$ & $4,157,450.00$ & $4,011,650.00$ & $4,157,450.00$ \\
\hline 8 & Discounted NCF & $2,390,672.14$ & $2,781,886.75$ & $2,588,051.64$ & $2,585,916.10$ & $2,405,735.75$ & $2,310,085.63$ & $2,236,263.14$ & $2,234,417.88$ & $2,078,729.07$ & $2,077,013.79$ \\
\hline 9 & Cumulative discounted NCF & $28,768,935.05$ & $31,550,821.80$ & $34,138,873.45$ & $36,724,789.54$ & $39,130,525.29$ & $41,440,610.92$ & $43,676,874.07$ & $45,911,291.94$ & $47,990,021.02$ & $50,067,034.81$ \\
\hline
\end{tabular}




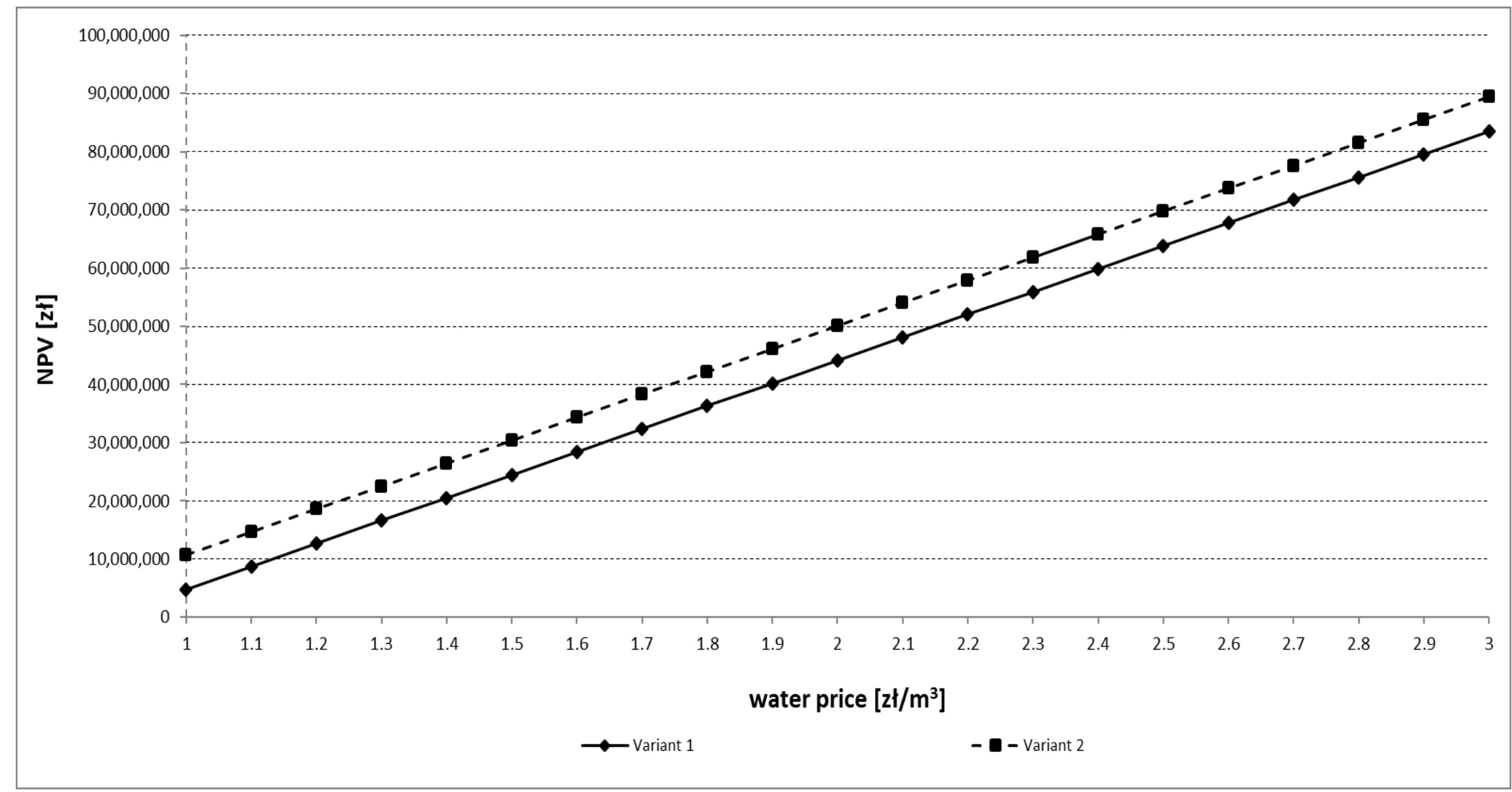

Figure 3. The sensitivity analysis of NPV relating to water price. 


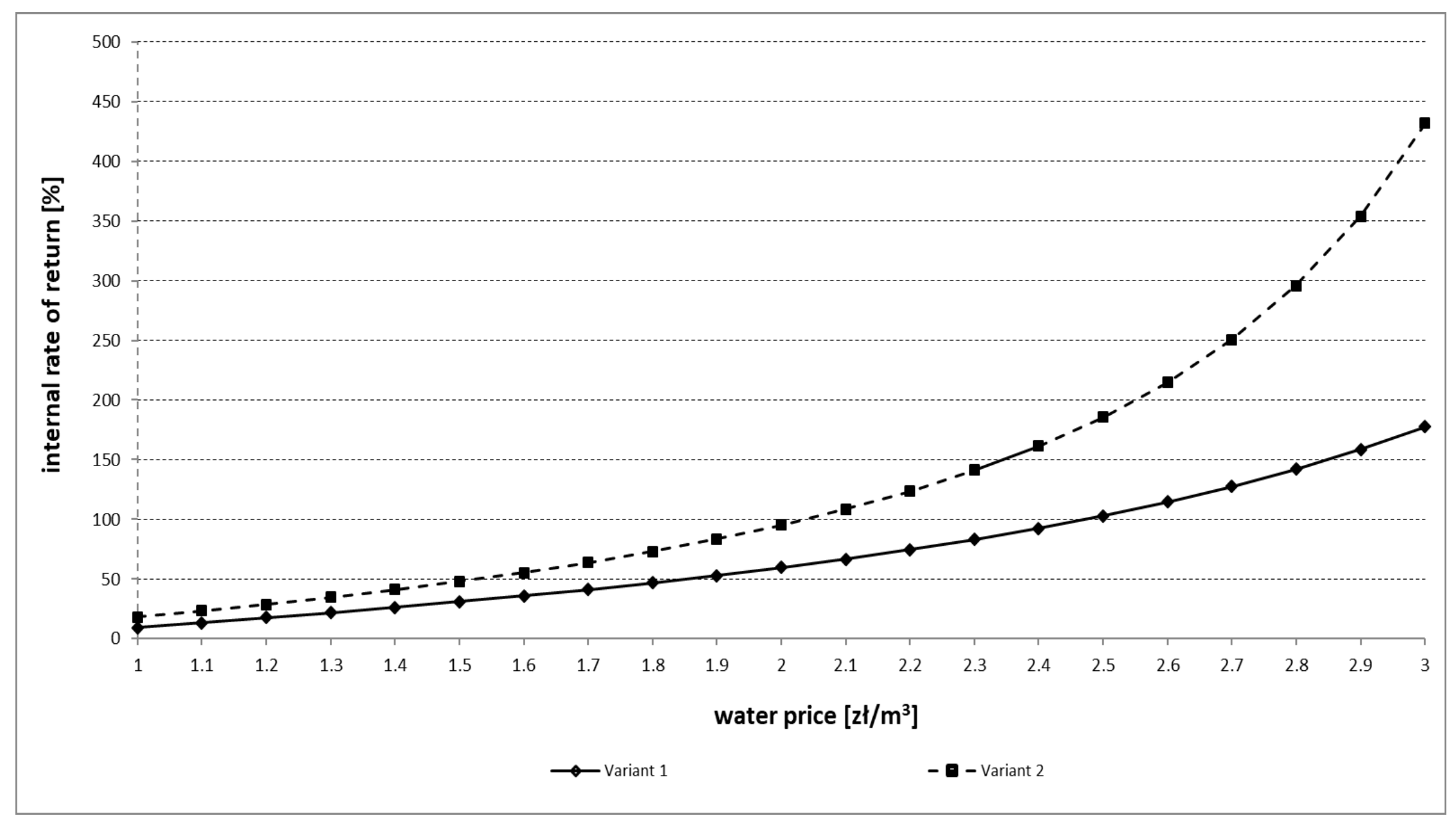

Figure 4. The sensitivity analysis of IRR relating to water price. 
- Variant 2 - the system of coagulation, sedimentation and a pressure ultrafiltration.

Economic and financial data and calculated values of net cash flows for both variants in the period of 20 years are given in Table 1 (Variant 1) and Table 2 (Variant 2).

Table 3.

The comparison of economic effectiveness indicators in analysed variants of treatment systems

\begin{tabular}{|l|c|c|c|}
\hline Id. & Economic effectiveness indicators & Variant 1 & Variant 2 \\
\hline 1. & Net Present Value, NPV & 44152152 PLN & 50067035 PLN \\
\hline 2. & Internal Rate of Return, IRR & $59.58 \%$ & $95.18 \%$ \\
\hline 3. & Discounted Payback Period, DPP & 2 years 284.1 days & 2 years 29.5 days \\
\hline 4. & Profitability Index, PI & 7,80 PLN/PLN & 12.62 PLN/PLN \\
\hline 5. & NPV Ratio, NPVR & 4.37 PLN/PLN & 6.34 PLN/PLN \\
\hline 6. & Limit value of water price & 0.8775 PLN & 0.7271 PLN \\
\hline
\end{tabular}

Analysing data given in Table 3, both variants could be accepted due to economic criteria, they are highly profitable. Both solutions generate high net present value (in line with high internal rates of return) and short discounted payback period.

However, economically, Variant 2 should be assessed as the most profitable due to a higher NPV (44 152152 PLN) and IRR (59.58 \%) in comparison with Variant 1 (50 067035 PLN and 95.18 \%). Relatively lower capital expenditure in Variant 2 (7,9 mln PLN) results in a shorter discount payback period ( 2 years 29.5 days) in comparison with variant 1 ( 2 years 284.1 days). The profitability index in Variant 2 (12.62 PLN/PLN) is much higher than in Variant 1 (7,8 PLN/PLN).

A high internal rate of return for both variant reduces the risk of losing the profitability in a situation of growing capital cost on the monetary market. Comparing the limit value of water price i.e. the water price at which NPV is zero, a better solution is variant 2 (0.7271 PLN) in comparison with Variant 1 (0.8775 PLN). Concluding all above-mentioned indicators, Variant 2 i.e. the system of coagulation, sedimentation and a pressure ultrafiltration is a better solution.

Additionally, the analysis of NPV and IRR sensitivity was carried out on selected technological parameters of the water treatment system (relating to water price).

The NPVs are changing in the following range:

- Variant 1 - from 4819794 PLN (water price = 1.0 PLN/m3) to 83484510 PLN (water price $=3.0 \mathrm{PLN} / \mathrm{m}^{3}$ ),

- Variant 2 - from $10734676 \mathrm{PLN}$ (water price = 1.0 PLN/m3) to $89399393 \mathrm{PLN}$ (water price $=3.0 \mathrm{PLN} / \mathrm{m}^{3}$ ).

The values of IRR are changing in the following range:

- Variant 1 - from $9.29 \%$ (water price $=1.0 \mathrm{PLN} / \mathrm{m} 3)$ to $117.65 \%$ (water price $=$ 3.0 PLN $/ \mathrm{m}^{3}$ ),

- Variant 2 - from $18.17 \%$ (water price $=1.0 \mathrm{PLN} / \mathrm{m} 3$ ) to $431.74 \%$ (water price $=$ 3.0 PLN/ $/ \mathrm{m}^{3}$ ). 
The results of the cost analysis of both tested variants indicate that the use of pressure ultrafiltration as the final process is much more effective than the conventional treatment system based on rapid filtration and dynamic sorption. Each of these solutions has its pros and cons. From a technological point of view, the use of pressure ultrafiltration after properly carried out conventional coagulation is characterized by greater technological security in terms of obtaining the required value of SDI (Slit Density Index), which is a synthetic indicator for assessing the quality of water feeding osmotic membranes. Practically, until membranes are mechanically damaged, the installation is able to produce water of the required quality.

In case of the conventional system, the technological risk is higher. If rapid filters are improperly operated, suspended solids collected in a filter bed may get into the outflow and then flow to granular activated carbon filters and osmotic membranes, causing their fouling. The advantage of this solution, in turn, is the possibility of obtaining a much effective organic impurities removal than when using ultrafiltration. It is due to sorption process on activated carbon bed, which allows the removal of these fractions of natural organic matter that cannot be removed during conventional coagulation. This extends the life of the membranes and allows to produce demi water with lower total organic carbon content under certain circumstances.

Comparing Variants 1 and Variant 2 in terms of technology, their application is mainly determined by aspects not related to the applied water treatment unit processes. The use of coagulation pre-treatment allows the removal of most of impurities present in raw water, reducing the pollution load supplied to rapid filtration and sorption system in Variant 1 or to ultrafiltration in Variant 2. The basic factor determining economic efficiency is the operation of the pre-treatment system at the designed production capacity. However, even if the demand for water is lower per year, which results in lower use of activated carbon or extension of ultrafiltration membranes life, it will not affect the technological assessment of the variants.

To conclude, considering all the profitability indicators of the analysed variants of, the construction of the preliminary water treatment system, it should be emphasized that the most advantageous solution is Variant 2, i.e. the use of pressure ultrafiltration as a method of preparing water of quality that allows final feeding.

\section{Conclusions}

1. The calculation for both analysed variants indicate a large impact of unit processes on the investment and operating costs of pre-treatment systems prior to membrane demineralization process.

2. The lower economic efficiency of the conventional system is affected by the need to install a double filtration system: rapid filtration and GAC dynamic sorption. This 
results in significantly higher investment costs than in case of a membrane ultrafiltration system.

3. In terms of operating costs, the high cost of active carbon exchange in Variant 1 is decisive. The technological system assumes a two-year lifetime of the sorption bed. This is due to the inability to exploit the operation of carbon filters in the biosorption regime. Due to the properties of osmotic membranes, the risk of uncontrolled appearance of microorganisms in the water feeding the demineralization installation is unacceptable.

4. The adopted economic and financial parameters in the calculation model allow to state that the analysed pre-treatment variants of water purification are characterized by the following indicators of economic profitability:

- NPV: Variant 1 - 44152152 PLN, Variant 2 - 50067035 PLN,

- NPVR: Variant 1 - 4.37 PLN/PLN, Variant 2-6.34 PLN / PLN,

- IRR: Variant $1-59.58 \%$, Variant $2-95.18 \%$,

- PI: Variant 1 - 7,80 PLN/PLN, Variant 2 - 12,62 PLN/PLN,

- DPP: Variant 1 - 2 years 284.1 days, Variant 2 - 2 years 29.5 days.

The above-mentioned values of economic indicators point at Variant 2 i.e. the system of coagulation, sedimentation and a pressure ultrafiltration as a better solution.

\section{References}

1. Al-Juboori, R.A., and Yusaf, T. (2012). Biofouling in RO system: mechanisms, monitoring and controlling. Desalination, Vol. 301, pp. 1-23.

2. Berens, W., and Hawranek, P.M. (1993). Guide for preparation of the analysis of industrial feasibility studies, UNIDO. Warsaw: Information Centre Engineer.

3. Brehant, A., Bonnelye, V., and Perez, M. (2002). Comparison of MF/UF pretreatment with conventional filtration prior to RO membranes for surface seawater desalination. Desalination, Vol. 144, pp. 353-360.

4. Greenlee, L.F., Lawler, D.F., Freeman, B.D., Marrot, B., and Moulin, P. (2009). Reverse osmosis desalination: water sources, technology, and today's challenges. Water Resources, Vol. 43, pp. 2317-2348. doi:10.1016/j.watres.2009.03.010.

5. Gumińska, J., and Kłos, M. (2011). Evaluation of optimization of coagulation - experience with the operation of technological systems with sedimentation and dissolved air flotation. Gas Water Sanitary Techology, Vol. 5, pp. 194-197.

6. Gumiński, A., Kłos, M., and Gumińska, J. (2017). Economic aspects of application of pretreatment systems before granular activated carbon filtration. Architecture Civil Engineering Environment, Vol. 10(4), pp. 123-131. 
7. Haberkamp, J., Ruhl, A., Ernst, M., and Jekel, M. (2007). Impact of coagulation and adsorption on DOC fractions of secondary effluent and resulting fouling behaviour in ultrafiltration, Water Resources, Vol. 41(17), pp. 3794-3802, doi:10.1016/j.watres. 2007.05.029.

8. Henthorne, L. and Boysen, B. (2015). State-of-the-art of reverse osmosis desalination pretreatment. Desalination, Vol. 356, pp. 129-139, doi:10.1016/j.desal.2014.10.039.

9. Hoek, E.M.V., Allred, J., Knoell, T., and Jeong, B.H. (2008). Modeling the effects of fouling on fullscale reverse osmosis processes. Journal of Membrane Science, Vol. 314, pp. 33-49.

10. Huehmer, R.P. (2009). MF/UF pretreatment in seawater desalination: applications and trends In: Proceedings of World Congress in Desalination and Reuse, International Desalination Association, IDAWC/DB09-253, Dubai: UAE.

11. Jiang, S. et al. (2017). A review of reverse osmosis membrane fouling and control strategies. Science of the Total Environment, Vol. 595, pp. 567-583, doi: 10.1016/j.scitotenv. 2017.03.235.

12. Kim, J., and Kang, B. (2008). DBPs removal in GAC filter-adsorber. Water Resources, Vol. 42, pp.145-152.

13. LeChevallier, M.W., Becker, W.C., Schorr, P., and Lee, R.G. (1992). Evaluating the performance of biologically active rapid filters. Journal of the American Water Works Association, Vol. 84(4), pp. 136-46, doi:10.1002/j.1551-8833.1992.tb07339.x.

14. Lin, H., Zhang, M., Wang, F., Meng, F., Liao, B.Q., Hong, H., Chen, J., and Gao, W.A. (2014). Critical review of extracellular polymeric substances (EPSs) in membrane bioreactors: characteristics, roles in membrane fouling and control strategies. Journal of Membrane Science, Vol. 460, pp. 110-125.

15. Nguyen, V., Karunakaran, E., Collins, G., and Biggs, C.A. (2016). Physicochemical analysis of initial adhesion and biofilm formation of Methanosarcina barkeri on polymer support material. Colloids and Surfaces B: Biointerfaces, Vol. 143, pp. 518-525.

16. Randtke, S.J. (1998). Organic contaminant removal by coagulation and related process combinations. Journal of the American Water Works Association, Vol. 80, pp. 40-56, doi: 10.1002/j.1551-8833.1988.tb03037.x.

17. She, Q., Wang, R., Fane, A.G., and Tang, C.Y. (2016). Membrane fouling in osmotically driven membrane processes: a review. Journal of Membrane Science, Vol. 499, pp. 201-233, doi: 10.1016/j.memsci.2015.10.040.

18. Sierpińska, M., and Jachna, T. (2005). Rating of companies according to world standards. Warsaw: PWN.

19. Simpson, D.R. (2008). Biofilm processes in biologically active carbon water purification. Water Resources, Vol. 42, pp. 2839-2848, doi: 10.1016/j.watres.2008.02.025.

20. Voutchkov, N. (2010). Considerations for selection of seawater filtration pretreatment system. Desalination, Vol. 261, pp. 354-364, doi: 10.1016/j.desal.2010.07.002. 